\title{
Formas moleculares da gonadotrofina coriônica humana: características, ensaios e uso clínico
}

\author{
Molecular forms of human chorionic gonadotropin: characteristics, assays and clinical use
}

Sebastião Freitas de Medeiros $^{1}$, Robert John Norman ${ }^{2}$

\section{RESUM0}

A gonadotrofina coriônica hum ana (hCG) é estruturada pela combinação não covalente de duas subunidades, alfa $(\alpha \mathrm{hCG})$ e beta ( $\beta \mathrm{hCG})$, sintetizadas separadamente pelo tecido trofoblástico normal, mola hidatiforme, coriocarcinoma, células hipofisárias e tecidos tumorais de diversos tipos histológicos. A síntese da cadeia peptídica e sua glicosilação na célula secretora envolve complexa ação de várias enzimas. Esta complexidade resulta na secreção de moléculas heterogêneas. As diferentes formas moleculares secretadas podem ser encontradas no soro, urina e líquido amniótico de gestantes; soro, urina e vesículas em pacientes com mola hidatiforme ou coriocarcinoma e em fluidos biológicos de mulheres não grávidas e hom ens norm ais ou acometidos de tumores de diferente origem embrionária. Tanto a molécula hCG nativa, intacta,como suas subunidades nas form as livres e as variantes hCG hiperglicosilada (H-hCG), hCG clivada (N-hCG) e fragmento-núcleo de $\beta$ hCG (CF- $\beta h C G)$ têm aplicabilidade clínica relevante. Dependendo da forma molecular mais prevalente ou da proporção da molécula variante/molécula hCG intacta numa determinada condição clínica, há indicação para a dosagem específica de uma ou mais destas moléculas. Este texto revê o conhecimento básico e analisa o uso da hCG e suas variantes na detecção precoce da gravidez ectópica ou gestantes em risco de abortamento, na identificação precoce de anomalias cromossômicas êmbrio-fetais e estima o risco da gestação de evoluir com pré-eclâmpsia ou crescimento intra-uterino restrito. Examina, ainda, fora da gravidez, o emprego destas moléculas como marcadores laboratoriais de tumores com diferentes tipos histológicos e seguimento após a terapia inicial. Conclui-se ser útil o uso da dosagem de hCG e suas moléculas variantes na prática clínica, mas a dificuldade no desenvolvimento e obtenção de ensaios mais sensíveis e específicos restringe a aplicação mais universal destes marcadores hormonais.

PALAVRAS-CHAVE: Gonadotrofina coriônica; Beta hCG livre; Núcleo-fragmento de $\beta$ hCG; Formas moleculares de hCG

\section{ABSTRACT}

The human chorionic gonadotropin (hCG) results from a non-covalent linkage of two subunits, alpha ( $\alpha \mathrm{hCG}$ ) and beta ( $\beta \mathrm{hCG}$ ), separately synthesized by normal trophoblastic tissue, hydatiform mole, choriocarcinom a, pituitary cells, and tumoral tissues of different histologic types. The peptide chain and its further glycosylation in the secretory cell involves the complex action of different enzymes. This complexity results in the secretion of heterogeneous molecular forms. The different molecules might be found in serum, urine and amniotic fluid of pregnant women; serum, urine, and vesicles of patients with hydatiform mole or choriocarcinoma and in other biological fluids of normal non-pregnant women and men or patients with different embryonary types of cancer. Both the intact hCG molecule and its free subunits and the hyperglycosylated (H-hCG), nicked (N-hCG) and core fragment of $\beta$ hCG (CF- $\beta$ hCG) variant forms have relevant clinical use. Depending on the prevalent molecular form or the proportion of the variant form to the intact hCG in a determined clinical situation the measurement of a specific molecule is chosen. This review analyzes the clinical use of hCG and its related molecules in the early detection of ectopic pregnancy or patients with higher risk of abortion, in the identification of an embryo or fetus with chromosomal abnormalities, and in the evaluation of risk for preeclampsia or fetal growth restriction. The review also examines the use of hCG and variant forms as tumor m arkers. It is concluded that it is useful to measure hCG and/or related molecules in clinical practice, but difficulties in developing and achievement of more sensitive and specific new assays limit their use.

KEYWORDS: Chorionic gonadotropin; Free beta hCG; Beta-core fragment of hCG; M olecular form s of hCG

1 Professor Adjunto, Departamento de Ginecologia e Obstetrícia, Faculdade de Ciências Medicas, UFMT e Instituto Tropical de Medicina Reprodutiva e Climatério, Cuiabá (MT), Brasil.

2 Professor and Head of Reproductive Medicine at The Queen Elizabeth Hospital, Department of Obstetrics and Gynecology, University of Adelaide. Director of the Research Centre for Reproductive Medicine, Adelaide, South Australia, Australia.

Correspondência: Sebastião Freitas de Medeiros

Rua Marechal Deodoro, 1055, Apto. 1302 - Centro - 78005-101 - Cuiabá - MT - Fone: (65) 3322-7342 - Fax: (65) 3623-0079 - e-mail: de.medeiros@terra.com.br 


\section{Introdução}

A heterogeneidade na estrutura e composição da cadeia de peptídeos e ramificações de carboidratos da molécula da gonadotrofina coriônica humana (hCG) é achado comum no soro, urina, líquido amniótico e outros fluidos orgânicos. Do ponto de vista fisiopatológico existem várias possíveis razões para a heterogeneidade hormonal: 1) modificações estruturais na cadeia protêica, determinadas geneticamente, 2) modificações induzidas pelo meio hormonal durante a síntese e liberação da molécula, 3) existência de pró-hormônios, 4) polimerização de formas moleculares nativas nos fluidos orgânicos, 5) associação do hormônio com outras proteínas circulantes, 6) degradação metabólica $^{1,2}$. O significado metabólico e clínico das di- versas formas moleculares de hCG permanece em debate e investigação. Em paralelo à compreensão da estrutura química e do significado fisiológico das múltiplas formas moleculares, vários distúrbios associados com anormalidades estruturais na molécula nativa de hCG têm sido identificados.

Nesta revisão propõe-se examinar a composição protéico-glicídica da molécula de hCG padrão, analisar as vias metabólicas envolvidas na secreção e excreção deste hormônio, caracterizar as diferentes formas moleculares encontradas nos líquidos biológicos (Figura 1) e correlacioná-las com condições clínicas normais ou anormais, com o objetivo de dimensionar a importância de seu uso clínico. Além disso, destaca-se a importância do uso de ensaios específicos e sensíveis para dosar as diferentes moléculas, segundo as condições clínicas presentes.

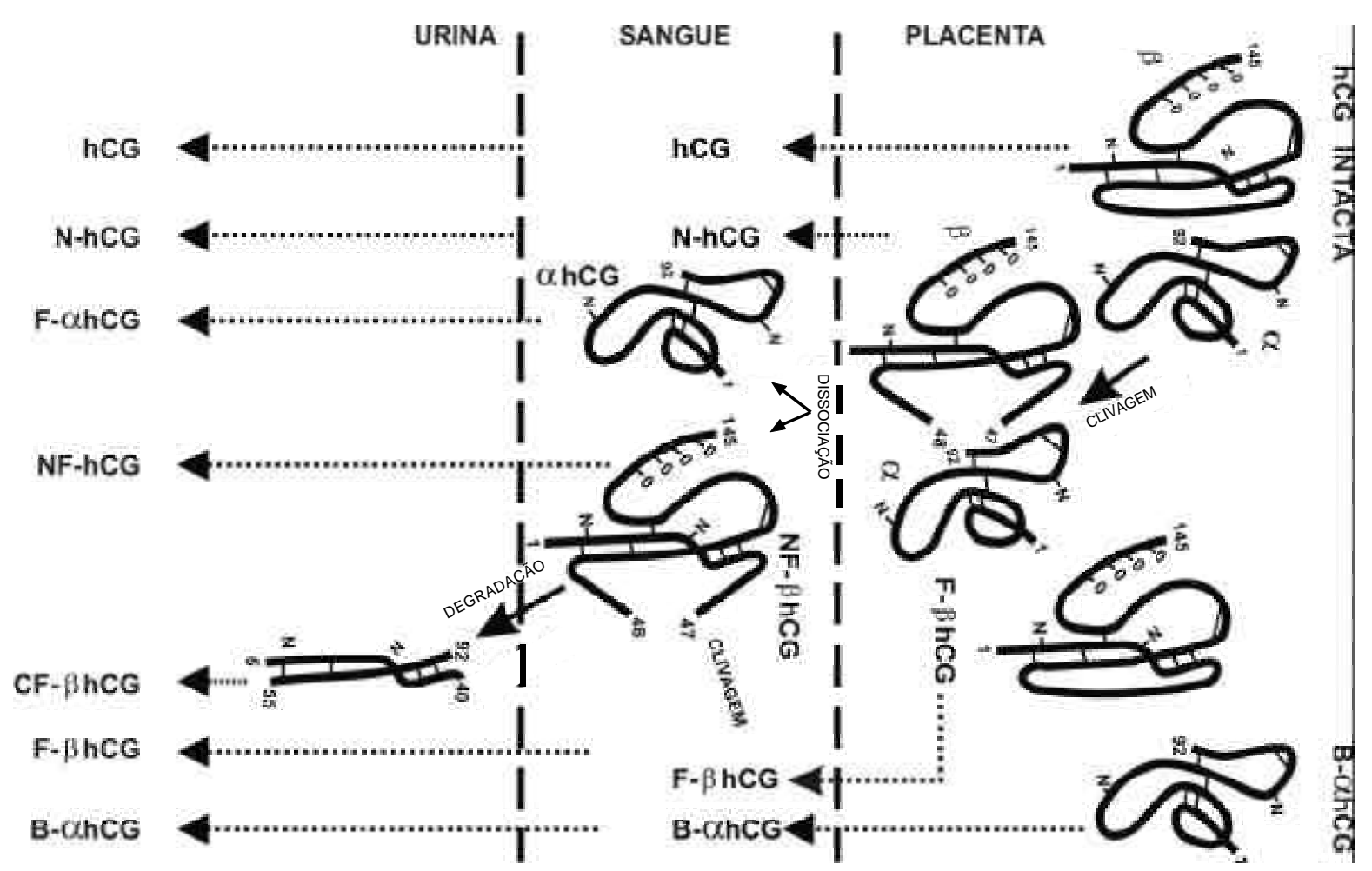

Figura 1 - Representação da estrutura de hCG e moléculas variantes na placenta, soro e urina. B = big, grande; $\mathrm{N}=$ nicked, clivada; $\mathrm{F}=$ free, livre; $\mathrm{CF}=$ core-fragment, fragmento-núcleo; $\mathrm{N}$ - = ramificação de carboidratos ligada à serina; O- = ramificação de carboidratos ligada à asparagina. Modificada da referência 7.

\section{Estrutura, Sintese e Metabolismo da Gonadotrofina Coriônica Humana}

A molécula de hCG tem peso molecular de aproximadamente 38.000 daltons, com $70 \%$ de sua estrutura representada pelo arcabouço protéico e $30 \%$ pelas ramificações e unidades de carboidratos $^{3}$. Está estruturada em duas subunidades. A subunidade alfa ( $\alpha \mathrm{hCG}$ ), com cadeia polipeptídica de 92 aminoácidos, é virtualmente idêntica às subunidades alfa das outras glicoproteínas hipofisárias numa mesma espécie. Ainda que as subunidades alfa sejam consideradas similares na seqüência de aminoácidos, podem existir diferenças marcantes na composição e complexidade das cadeias laterais de oligossacarídeos. Enquanto os oligossacarídeos da molécula da subunidade $\alpha$ hCG têm ácido siálico, galactose, $\mathrm{N}$-acetilglicosamina e manose, os oligossacarídeos das moléculas das subunidades alfa do hormônio luteinizante (LH) e do hormônio folículo-estimulante (FSH) contêm ácido siálico, galactose, $\mathrm{N}$-acetilgalactosamina e 
sulfato $^{4}$. A subunidade beta do hCG ( $\beta \mathrm{hCG}$ ) confere especificidade biológica e imunológica à molécula de hCG na sua forma dimérica completa. Embora seja estruturalmente semelhante às subunidades beta das outras glicoproteínas hipofisárias, a cadeia de aminoácidos da $\beta$ hCG possui 45 aminoácidos adicionais na cadeia peptídica e conteúdo de carboidrato completamente diferente das subunidades beta que compõem as moléculas de $\mathrm{LH}$ e $\mathrm{FSH}^{1}$.

Tanto a biosintese como o processamento da molécula de hCG assemelham-se ao de outros hormônios glicoprotéicos. As duas subunidades, $\alpha$ e $\beta$, influenciam-se mutuamente no processamento do dímero hCG. O conjunto de enzimas contido na célula secretora determina o tipo de processamento dos oligossacarídeos adicionados às subunidades alfa e beta. As subunidades são sintetizadas separadamente, numa proporção não balanceada, em resposta à transcrição genética dos mRNAs; a subunidade alfa é, na maioria das vezes, sintetizada em excesso ${ }^{3}$. Além da produção coordenada dos polipetídeos das duas subunidades, o processo de montagem da molécula de hCG nas organelas citoplasmáticas requer a glicosilação seqüencial pós-translacional destes peptídeos, processamento dos oligossacarídeos, formação das pontes dissulfidicas de cada subunidade e associação não covalente das duas subunidades préformadas ${ }^{3}$. Esta seqüência acontece enquanto as moléculas de hCG são translocadas ao longo da via secretora, desde o local de síntese no retículo endoplasmático rugoso (RER) até a superfície celular. A combinação destas subunidades modula a extensão do processo de glicosilação ${ }^{4}$.

As duas subunidades formadoras de toda a molécula de hCG são transcritas por genes diferentes. Enquanto a subunidade alfa é codificada por um único gene, a subunidade beta é transcrita por uma família de pelo menos seis genes ${ }^{5}$. Prébeta e pré-alfa são sintetizadas como peptídeos imaturos de maior peso molecular contendo a seqüência específica e a extensão do peptídeo sinalizador. A formação das subunidades envolve a clivagem e remoção co-translacional do peptídeo sinalizador por peptidases microssômicas, enquanto a cadeia peptídica encontra-se ainda no interior dos ribossomas. Imediatamente antes de os oligossacarídeos serem adicionados à cadeia de polipeptídeos, a molécula é liberada nos canais do RER e transportada ao aparelho de Golgi, organela onde é glicosilada ${ }^{3}$. Como visto, a adição das cadeias de carboidratos às subunidades envolve uma série de modificações pela ação seqüencial de várias enzimas imediatamente antes de as subunidades serem secretadas. A glicosilação ligada ao resíduo asparagina (N-ligada) das duas subunidades envolve a transferência em bloco do oligossacarídeo pré-montado para sítios específicos de resíduos asparagina na cadeia protéica. A glicosilação ligada ao resíduo serina (O-ligada) da subunidade beta envolve a adição seqüencial e individual de cada monossacarídeo por enzimas do RER e aparelho de Golgi ${ }^{3,4}$.

Após a adição das unidades de carboidratos, a associação das subunidades alfa e beta formam o dímero completo no RER, numa fase em que ambas as subunidades ainda têm alto conteúdo de manose. Esta é uma característica das formas imaturas de hCG. A ligação entre as subunidades alfa e beta produzidas não é completa, e significantes frações dos precursores intracelulares alfa e beta não combinam. O resultado é a secreção de formas livres de $\alpha$ hCG ou $\beta$-hCG segundo o tipo de tecido ou a condição clínica existente. Todo o processo de glicosilação da molécula nativa do hCG só é completado após a montagem do dímero-hCG, um pouco antes de sua secreção ${ }^{3}$.

Para expressar sua atividade biológica, a molécula de hCG liga-se ao receptor específico na membrana da célula-alvo. A extensão da atividade biológica é dependente da expressão ou estrutura da molécula, e o sinal de transdução envolve modificações conformacionais, em uma ou nas duas subunidades. Como a dissociação das subunidades, a perda de certas regiões peptídicas específicas ou a perda de alguns resíduos de carboidratos podem afetar tanto a atividade biológica como a imunológica, aceita-se que, além da estrutura conformacional do dímero, a função biológica do hCG seja dependente de regiões específicas das cadeias protéicas e determinados resíduos de carboidratos ${ }^{6}$.

Quando dissociadas, as subunidades alfa e beta são destituídas de atividade biológica e a recombinação posterior destas restaura apenas $80 \%$ da atividade original. Estas observações indicam a ocorrência de alguma alteração conformacional após a reassociação das subunidades e demonstram que as duas subunidades participam da conformação adequada do hormônio natural ${ }^{3}$. Portanto, embora a especificidade biológica seja conferida pela subunidade beta, significante atividade hormonal é expressada apenas após a formação do heterodímero alfa-beta. Ainda que a porção ligante da molécula ao receptor esteja localizada na superfície da subunidade beta, grupos de aminoácidos específicos na superfície da subunidade alfa parecem críticos para a atividade, indicando que o sítio ativo da molécula do hCG inclui regiões estruturais ou resíduos de aminoácidos específicos das duas subunidades ${ }^{1}$. De um modo geral, as ramificações de carboidratos do hCG são necessárias para a correta conformação de toda a 
molécula, interação entre as subunidades alfa e beta e proteção contra a degradação proteolítica ${ }^{3}$. Enquanto a atividade biológica do hCG diminui com a desialilação progressiva e a remoção parcial ou completa de carboidratos internos ao ácido síalico, a remoção de certos resíduos de carboidratos aumenta a afinidade da molécula pelo receptor ${ }^{6}$.

Cerca de $22 \%$ das moléculas de hCG são excretadas sem qualquer modificação. Os $78 \%$ restantes das moléculas são retidos no corpo, captadas por outros tecidos ou excretadas pelo rim com a estrutura molecular alterada ${ }^{7}$. Na gestação, os mecanismos que modulam tanto a filtração glomerular quanto a captação tubular das moléculas de hCG parecem variar com a idade gestacional. É provável que a micro-heterogeneidade nas cadeias laterais de carboidratos da molécula, variável segundo a fase da gestação, module a taxa de captação tubular e responda pelo tipo de proteina terminal excretada ${ }^{8,9}$. Com o avançar da gestação a molécula do hCG torna-se mais ácida e, nesta forma ácida, cruza a membrana basal do glomérulo mais facilmente. No parênquima renal a molécula de hCG é encontrada principalmente no interior das células do túbulo proximal e, nestas células, é degradada e excretada como fragmentos menores ou resíduos individuais de aminoácidos ou carboidratos ${ }^{9}$.

Além da excreção renal, parte do hCG segue via metabólica alternativa no corpo. Tecidos como fígado e ovário também metabolizam este hormônio. As formas de hCG destituídas de ácido siálico são rapidamente retiradas de circulação pelo fígado. Neste órgão, as moléculas captadas distribuem-se ao longo dos sinusóides e não no interior do hepatócito, indicando que a captação é feita pelas células de Kupffer ${ }^{9}$. No ovário, a captação de hCG parece ser limitada pela disponibilidade do receptor específico ${ }^{10}$. Estudos experimentais têm mostrado que o tecido ovariano internaliza o hCG e degrada-o a fragmentos menores. Quando hCG radioativa é injetada no organismo, quantidade apreciável de moléculas é internalizada e degradada nas células da granulosa e teca luteinizadas. Além disso, células da granulosa humana expostas ao hCG in vitro liberam moléculas menores no meio de cultura, indicando metabolismo ativo da hCG neste compartimento ${ }^{11}$.

\section{Gonadotrofina Coriônica Humana Intacta}

Na gestação normal as moléculas intactas de hCG (Figura 1) começam a ser detectadas no sangue materno 2 a 3 semanas após a concepção.
Sua concentração aumenta exponencialmente no primeiro trimestre, dobrando a cada dois dias e alcança as maiores concentrações entre a $11-13^{\mathrm{a}}$ semana. No segundo trimestre diminui em $80 \%$ até a $20^{\mathrm{a}}$ semana e permanece nesta concentração até o termo ${ }^{4}$. Tanto concentrações elevadas como diminuídas de hCG intacta têm sido associadas a alterações maternas ou feto-placentárias, tornando-se, sua quantifição, método investigado para identificação de pré-eclâmpsia, crescimento intra-uterino restrito (CIUR) e trissomias ${ }^{12,13}$.

A dosagem de hCG depende do reconhecimento imunológico de parte da molécula e os ensaios que quantificam apenas o dímero hCG, sem incluir suas formas variantes, devem ser escolhidos quando o objetivo for medir as concentrações da molécula intacta. $\mathrm{O}$ grande número de anticorpos mono e policlonais e técnicas disponíveis podem gerar confusão e resultados inconsistentes, sendo então necessário o uso de anticorpos que reconheçam epitopos sobre porções nas duas subunidades, alfa e beta. Infelizmente, desde 1972, a maioria dos ensaios comercialmente disponiveis identificam tanto a molécula intacta como sua subunidade beta na forma livre ${ }^{1}$. Análise de trinta e nove ensaios disponiveis para hCG e moléculas relacionadas identificou apenas nove específicos para a molécula de hCG intacta ${ }^{8}$. Estudo recente, incluindo os dez ensaios mais utilizados nos Estados Unidos da América, mostrou que apenas um deles (Dade Dimension RXL, Dade Behring Ltd.) quantifica a molécula de hCG, sem inclusão, na dosagem, da subunidade beta livre ${ }^{14}$. Padrões virtualmente destituídos de formas contaminantes para dosar a molécula de hCG intacta e suas variantes foram recentemente disponibilizados pela Organização Mundial de Saúde (1stResearch Reagents) com o objetivo de facilitar a comparação entre os diferentes ensaios e laboratórios ${ }^{15}$.

Como anormalidades trofoblásticas têm papel central na fisiopatologia da pré-eclâmpsia, tem sido encontrada produção aumentada de hCG nesta condição, acreditando-se que sua maior produção na pré-eclâmpsia seja uma resposta benéfica à hipóxia trofoblástica, favorecendo a angiogênese, vasodilatação e invasão trofoblástica ${ }^{16}$. Estudos clínicos mostram elevação consistente dos níveis de hCG de acordo com a gravidade da préeclâmpsia ${ }^{17}$; sugerindo seu uso como potencial marcador indicativo de pré-eclampsia no segundo trimestre $^{18}$. Niveis entre 2,0 e 2,5 múltiplos da mediana (MoM) são considerados positivos ${ }^{12}$. Ainda que haja boa correlação entre os níveis de hCG e peróxido de hidrogênio, a aplicabilidade clínica da dosagem da molécula intacta de hCG para dimensionar o estresse oxidativo placentário e o 
prognóstico na pré-eclâmpsia requer mais estudos. Como pode atuar diretamente atenuando a tensão vascular arterial e promovendo a diferenciação sincício-trofoblástica e invasão das artérias espiraladas, baixos níveis de hCG podem estar envolvidos ainda nos casos que resultam em CIUR $^{19}$.

Todos os tumores trofoblásticos produzem a molécula de hCG intacta. Micro-heterogeneidade na composição de carboidratos ocorre na molécula produzida por tumores, sem afetar a imunorreatividade e amplificando a bioatividade ${ }^{20}$. Tanto com o objetivo diagnóstico como no seguimento de situações anormais, a molécula de hCG intacta deve ser quantificada em amostras de soro ou plasma, mas não da urina ${ }^{1}$. Os tumores de pior prognóstico secretam a subunidade beta em maiores proporções e os ensaios empregados devem discriminar o dímero hCG da subunidade $\beta$ hCG livre, para quantificação exata e conduta adequada. Tumores de células germinativas femininas (disgerminoma, carcinoma embrionário) e masculinas (seminomas, não-seminomas) expressam hCG em quantidades suficientes para detecção no soro de 15 a $72 \%$ dos pacientes acometidos ${ }^{21}$. Níveis de hCG superiores a 100-1000 UI/mL nestes tumores indicam maior risco e pior prognóstico. Em adição aos tumores de células germinativas, cânceres de bexiga, rim, próstata, fígado, pulmão, mama e cólon-reto expressam hCG em variável proporção, principalmente a forma $\beta$ hCG livre ${ }^{22}$.

$\mathrm{O}$ uso de marcadores bioquímicos para a identificação de trissomias tornou-se comum na prática obstétrica. Vários estudos têm proposto a dosagem sérica de hCG intacta para discriminar gestações normais de gestações com síndrome de Down. Nos casos com trissomia 21, a hCG está particularmente aumentanda entre a $11^{\mathrm{a}}$ e a $14^{\mathrm{a}}$ semana ${ }^{23}$. Ainda que haja elevação dos seus níveis, nesta fase a molécula intacta de hCG não parece ser a melhor alternativa como marcador bioquímico, sendo os ensaios capazes de identificar apenas $63 \%$ dos casos, com taxa de falso-positivo de $5 \%$. Os resultados, em MoM, variam entre 1,11 e 1,91 no primeiro e segundo trimestres ${ }^{24,25}$. O significado do aumento de hCG no segundo trimestre permanece incerto e parece estar associado com a redistribuição do fluxo cerebral, neuroesteroidogênese e desenvolvimento das funções autonômicas e sensoriais em fetos acometi$\operatorname{dos}^{26}$. Na trissomia 13 as concentrações de hCG também estão aumentadas mas, pelo contrário, estão diminuídas na trissomia $18^{13}$. Além disso, a diploidia diândrica tem sido caracterizada por marcada elevação de hCG e a digênica por concentrações muito baixas desta gonadotrofina. Nestas situações as concentrações de hCG aumenta- das resultam de hiperplasia trofoblástica e as baixas são conseqüências do pequeno desenvolvimento da unidade feto-placentária ${ }^{27}$.

\section{Gonadotrofina Coriônica Humana Hipergilicosilada}

Como os monossacarídeos dos núcleos das cadeias de carboidratos da molécula de hCG são relativamente homogêneos, a variação na estrutura dos carboidratos ocorre principalmente nos resíduos periféricos; no entanto, a natureza e a extensão desta glico-heterogeneidade permanece pouco compreendida. Como a molécula de hCG pode ser sintetizada em muitos tecidos e/ou muitas condições clínicas, alguns destes tecidos são incapazes de sintetizar a cadeia completa de carboidratos, resultando em formas moleculares hipoglicosiladas. Outros tecidos, por outro lado, incapazes para clivar o precursor altamente glicosilado da molécula, dão origem às formas hiperglicosiladas. Micro-heterogeneidade nos carboidratos pode ainda ser resultado de moduladores locais diversos ou do ambiente hormonal existente no momento de síntese da molécula ${ }^{5}$.

Uma forma molecular maior (38.500-40.000 daltons), com maior bioatividade e hiperglicosilada de hCG (H-hCG), também denominada antígeno invasivo do trofoblasto, é produzida pelo citotrofoblasto, contém uma antena adicional sobre as cadeias laterais dos carboidratos e mostra estrutura mais complexa com ramificações biantenária e triantenária. As cadeias de carboidratos da molécula de hCG intacta, padrão, contêm entre 8 e 15 ácidos siálicos terminais, mas esta forma hiperglicosilada contém entre 8 e 19 resíduos $^{28}$. H-hCG é produzida por células trofoblásticas invasivas e pouco diferenciadas, de modo independente da molécula intacta padrão, sendo a forma molecular de hCG predominante nas primeiras três a quatro semanas de gravidez. A partir daí, diminui rapidamente, permanecendo em pequena proporção, quando comparada com a da molécula de hCG intacta, durante toda gravidez, como resultado da predominância da função do sincíciotrofoblasto bem diferenciado. Logo, é a forma preferível para o diagnóstico precoce de gravidez e da mola hidatiforme e suas complicações ${ }^{29}$. Como a maioria dos ensaios imunológicos disponíveis para dosar hCG intacta inclui esta molécula, sua presença pode ser fonte das diferenças quantitativas encontradas entre os diferentes testes ${ }^{15}$. Esta forma hiperglicosilada é encontrada tanto no soro como na urina e pode ser dosada nestes dois líquidos orgânicos. Há cerca de seis anos foi desenvolvido um teste quimioiluminométrico com dois an- 
ticorpos monoclonais ( $\beta 207, \beta 152)$ capaz de dosá-la separadamente ${ }^{30}$. Mais recentemente, este ensaio foi aperfeiçoado de tal modo que exibe reação cruzada menor que 3,5\% com todas as outras formas moleculares de $\mathrm{hCG}^{31}$. Do mesmo modo que a molécula de hCG intacta, esta forma pode ser encontrada em diferentes proporções em mulheres grávidas normais e outras condições normais ou não.

H-hCG é a forma mais comum encontrada no coriocarcinoma e tende a ser elevada tanto no primeiro como no segundo trimestre no soro e urina de gestantes com fetos portadores da síndrome de Down. Nesta síndrome, seus níveis, dados em MoM, estão 3,5 a 9,5 vezes maiores quando comparados com aqueles verificados em gestantes com fetos normais. Sua detecção é positiva em cerca de $45-80 \%$ dos fetos acometidos, com falso-positivo de $5 \%{ }^{32}$. Este resultado é equiparável ao encontrado com a dosagem de hCG intacta no segundo trimestre. A taxa de detecção pode aumentar para $85 \%$, diminuindo a taxa de falso-positivo em $26 \%$, quando esta forma molecular for dosada também na urina. A dosagem de H-hCG urinária como teste de rastreamento da síndrome de Down parece mesmo promissora ${ }^{33}$. Atualmente, nenhum marcador, e mesmo o emprego de testes múltiplos, alcança a sensibilidade observada com a H-hCG para detectar a trissomia 21. Esta glicoproteína tem, no entanto, pequena expressão na identificação de fetos com trissomia 18, situação em que seus valores são cerca de dez vezes menores do que os observados em gestantes com fetos normais ${ }^{34}$.

Importante associação negativa entre os níveis de $\mathrm{H}$-hCG e o desenvolvimento subsequente de pré-eclâmpsia foi verificada recentemente. Modificações nas concentrações de H-hCG de 0,9 MoM para 0,1 MoM entre a 14 e a $21^{\text {a }}$ semana de gravidez indicam elevação do risco de préeclampsia em cerca de dez vezes ${ }^{35}$. Este decréscimo nas concentrações de H-hCG é atribuído à rápida diminuição na sua produção, como conseqüência de baixa capacidade ou falha de invasão trofoblástica. Sua utilidade clínica nesta área, como marcador indicativo, ainda não foi estabelecida. A composição de carboidratos também varia consideravelmente na molécula de hCG produzida por tumores ${ }^{20}$. Entre 48 e $100 \%$ das moléculas de hCG produzidas pelo coriocarcinoma são hiperglicosiladas e respondem pelo comportamento invasivo destas células ${ }^{28,29}$.

\section{Gonadotrofina Coriônica Humana Clivada}

A forma hCG clivada (N-hCG, $\mathrm{N}$ do inglês nicked) sofre clivagem entre os peptídeos 47 e 48 da cadeia polipeptídica do dímero hCG (Figura 1) e menos freqüentemente, como visto em alguns casos de coriocarcinoma, entre os resíduos 43 e 44 ou 44 e $45^{28}$. As concentrações desta forma molecular são paralelas às da molécula de hCG intacta ao longo da gravidez e representam uma proporção de $9 \%$ em relação à molécula não clivada ${ }^{32}$. No segundo mês de gravidez, esta proporção aumenta para $21 \%$, permanecendo nesta porcentagem até o final da gestação ${ }^{33}$. As proporções na urina são iguais às encontradas no soro, aumentando de 8 a $31 \%$ ao longo da gravidez. A NhCG é molécula instável, não secretada pelo trofoblasto nesta forma, e resulta da clivagem de hCG intacta pelas enzimas tripsina e elastase produzidas pelos macrófagos associados às células trofoblásticas logo após deixar a célula secretora ${ }^{36}$.

Após a clivagem e formação de N-hCG, a atividade biológica diminui em aproximadamente 80\%. Do mesmo modo, há redução da capacidade de ligação aos anticorpos monoclonais disponíveis na maioria dos ensaios usados para dosar a molécula intacta de $\mathrm{hCG}^{35}$. Este fato contribui significativamente com a discrepância observada entre os resultados obtidos em várias condições clínicas com os diferentes ensaios comercialmente disponiveis ${ }^{37}$. Ensaio imunométrico incluindo como reagentes dois anticorpos monoclonais $(\beta$ $151, \beta 604)$, capazes de distinguir a N-hCG urinária da molécula de hCG intacta, foi desenvolvido pelo grupo do Prof. Steven Birken, na Universidade de Columbia, EUA, e pode ser usado na prática clínica. Este ensaio apresenta apenas 2,5\% de reação cruzada com a molécula de hCG intacta ${ }^{38}$.

A proporção de moléculas de hCG clivadas tem sido descrita como maior no soro e urina de indivíduos com pré-eclâmpsia, gestantes com fetos portadores de trissomia 21 , neoplasias trofoblásticas e pacientes com câncer de testículo ou bexiga. É, ainda, a principal forma molecular de hCG nas semanas seguintes ao esvaziamento molar ou ao tratamento quimioterápico de mola hidatiforme ou coriocarcinoma ${ }^{36}$. Em gestantes com pré-eclâmpsia os níveis séricos de N-hCG são cerca de $30-40 \%$ mais elevados, se comparados com os niveis encontrados em gestantes normotensas ${ }^{39}$. A elevação da forma clivada de hCG é explicada pelo aumento da ativação leucocitária nas gestantes com pré-eclâmpsia ${ }^{40}$. A presença de N-hCG em pacientes com neoplasia trofoblástica e tumores de células germinativas parece ter importância clínica. Concentrações elevadas de N-hCG foram detectadas no soro de indivíduos com câncer testicular seminomatoso e não seminomatoso. Nas amostras urinárias destes indivíduos esta forma de hCG pode ser a mais prevalente ${ }^{41}$. Os estudos são ainda escassos, talvez pela dificuldade de acesso ao ensaio imunológico específico, limitando seu emprego em larga escala. 


\section{Subunidade Beta Livre da Gonadotrofina Coriônica Humana}

As concentrações de $\beta$ hCG livre (F- $\beta$ hCG, F do inglês free), nas formas clivada ou não, variam em paralelo com as concentrações de hCG no soro e urina de gestantes normais, alcançando pico ao redor da $10^{\mathrm{a}}$ semana $^{8}$. Em proporção à hCG, sua concentração é de apenas $0,9 \%$ no segundo mês, declinando para 0,5\% no final da gravidez. Proporções maiores de F- $\beta$ hCG, entre 9 e $40 \%$, podem ser encontradas na urina. A existência de formas moleculares heterogêneas da subunidade beta da hCG também é achado comum ${ }^{37}$. Mesmo as preparações urinárias altamente purificadas da $\beta$ hCG não são homogêneas. Uma vez que radioensaios desenhados para detectar apenas a subunidade $\beta$ hCG livre, não combinada com a subunidade alfa, utilizam anticorpos específicos para determinados epitopos na molécula, a existência desta heterogeneidade pode ter importância em determinadas condições clínicas ou quando a quantificação exata da $\beta$ hCG for parâmetro importante no seguimento de determinados pacientes ${ }^{1,42}$. Heterogeneidade mais acentuada, seja no comportamento imunológico ou nas propriedades químicas da $\beta$ hCG, é encontrada nas moléculas secretadas por trofoblasto anormal ou outros tecidos, usualmente neoplásicos ${ }^{37}$.

As formas de $\beta$ hCG com importância clínica são as moléculas livres (F- $\beta$ hCG) detectadas na gestação e tumores não trofoblásticos ${ }^{1}$, as chamadas formas pré-beta encontradas na placenta e as subunidades $\beta$ hCG clivada ou hiperglicolisada, encontradas tanto na gravidez como em tumores trofoblásticos e não trofoblásticos ${ }^{1}$. Assim, formas de $\beta$ hCG com as cadeias glicídicas heterogêneas são mais comuns. Moléculas com cadeias grandes de oligossacarídeos ligados à serina da extensão carboxiterminal, moléculas com alto conteúdo de manose ou com alto teor de ácido siálico têm sido encontradas em extratos placentários normais ou no coriocarcinoma ${ }^{37}$. No soro de gestantes normais as concentrações de F- $\beta$ hCG são 200 vezes menores que a concentração do dímero da molécula de hCG, mas na urina a F- $\beta$ hCG é uma das formas predominantes desde o início da gravide $z^{42}$. Ensaios, incluindo anticorpos monoclonais, para dosar apenas a F-ßhCG são disponiveis e usados para a quantificação da molécula livre como marcador de determinadas condições anormais ${ }^{1,43,44}$.

$\mathrm{O}$ valor do uso clínico de $\mathrm{F}$ - $\beta$ hCG como marcador indicativo da evolução da gravidez tem sido examinado em poucos centros. Baixos níveis desta molécula no soro de gestantes no primeiro trimestre têm sido associados a interrupções es- pontâneas da gravidez antes de 22-24 semanas, ao desenvolvimento de pré-eclâmpsia, crescimento intra-uterino restrito e, mesmo, parto prematuro $^{45}$. Quando dosada mais tardiamente, entre a $11^{\mathrm{a}}$ e a $14^{\mathrm{a}}$ semana, parece não ter valor indicativo de qualquer complicação ${ }^{44}$. Níveis mais elevados de F- $\beta$ hCG podem ser encontrados em gestantes que desenvolvem pré-eclâmpsia, tanto na forma precoce como tardia. O valor limitrofe discriminativo de ter ou não risco de desenvolver préeclâmpsia é de 2,0 MoM ou $41.000 \mathrm{mUI} / \mathrm{mL}^{18,46}$. Permanece em debate seu valor indicativo de acordo com o número de gestações ou a forma clínica da pré-eclâmpsia. A F- $\beta$ hCG é largamente usada como marcador das trissomias, aneuploidias fetais e tumores epiteliais no adulto. Mesmo na sua forma livre, esta molécula parece exercer funções próprias nos tecidos, com atividade inibitória ou estimuladora do crescimento celular ${ }^{47}$.

Como marcador bioquímico das triploidias, a F- $\beta$ hCG está elevada na triploidia de origem paterna (diândrica), que cursa com placentas grandes ou mesmo com degeneração molar parcial, e baixa na triploidia de origem materna (diginica), quando a placenta é pequena e pouco desenvolvida ${ }^{45}$. Seus níveis séricos, em MoM, são da ordem de 8,04 nos casos de tripoidia de origem paterna e de 0,18 nos de origem materna, com mediana de 4,59 $\mathrm{MoM}^{48}$. Quando a F- $\beta$ hCG é associada a outros marcadores, pode identificar mais de $90 \%$ dos fetos com triploidia dos dois fenótipos. Na identificação de trissomias a dosagem de F- $\beta$ hCG é importante nos dois trimestres iniciais da gravidez. Na gravidez com sindrome de Down a F- $\beta$ hCG pode identificar até $95 \%$ dos fetos acometidos, seguindo modelo com taxa de falso-positivo fixa em $5 \%{ }^{49}$. Nesta trissomia 21 , os níveis de F- $\beta$ hCG estão elevados no primeiro trimestre e permanecem ainda elevados no segundo. Seus valores, em MoM, são entre 1,4 e 2,8 vezes maiores no primeiro e segundo trimestres, respectivamente ${ }^{50}$. Na urina de gestantes com sindrome de Down a F-âhCG também está elevada na ordem de 2,6 MoM maiores do que em gestantes com fetos normais ${ }^{51}$. Nos casos de trissomia 18 os níveis desta subunidade estão baixos no primeiro trimestre e diminuem de maneira mais acentuada no segundo. Na trissomia 13 , os níveis de $\mathrm{F}$ $\beta$ hCG estão diminuídos nos dois trimestres iniciais, na mesma dimensão ${ }^{44,52}$.

\section{Subunidade Alfa Livre da Gonadotrofina Coriônica Humana}

Além da subunidade alfa nativa de hCG $(\alpha h C G)$, formas de diferentes tamanhos ou com 
diferentes pesos moleculares e capacidade para se combinar com a subunidade $\beta$ hCG têm sido detectadas em várias fontes. A $\alpha$ hCG é heterogênea. Cerca de $70 \%$ das moléculas produzidas na placenta normal têm cadeia de aminoácidos com a seqüência Ala - Pro - Asp - $\mathrm{NH}_{2} 20 \%$ iniciam com Val- $\mathrm{NH}_{2}$ e $10 \%$ com Asp - Val - $\mathrm{NH}_{2}{ }^{28}$. Formas diferentes, seja com glicosilação excessiva ou escassa, são comumente secretadas em placentas normais. $\alpha \mathrm{hCG}$, com diferentes modificações estruturais, são também produzidas em tecidos não placentários ${ }^{8}$. A $\alpha$ hCG isolada da urina de mulheres após a menopausa tem peso molecular maior que a $\alpha$ hCG dissociada do dímero-hCG produzida pela placenta ou adenohipófise. Tem-se detectado uma forma molecular hiperglicosilada tanto em gestantes normais como em indivíduos com tumores. Forma molecular grande (BohCG, B do inglês big), contendo uma cadeia peptídica maior, é comum no coriocarcinoma e células do tumor carcinóide gástrico. Uma forma pequena (S- $\alpha \mathrm{hCG}, \mathrm{S}$ do inglês small), com perda de alguns aminoácidos na cadeia peptídica, pode ser também identificada na gravidez normal ou indivíduos com tumores não trofoblásticos ${ }^{53}$. O significado das diferentes moléculas e os fatores que induzem sua sintese e secreção ainda são desconhecidos.

A presença de uma forma molecular madura, grande e livre ( $\mathrm{F}-\alpha \mathrm{hCG}, \mathrm{F}$ do inglês free), tem sido detectada nas preparações comerciais de hCG, urina e soro de gestantes, extratos placentários, hipófise e tumores ${ }^{53,54}$. Seu maior tamanho é resultado de maior conteúdo de fucose e ácido siálico e maior proporção de carboidratos com estrutura biantenária ${ }^{55}$. A F- $\alpha$ hCG é regulador parácrino da secreção da prolactina durante a gravidez, e suas concentrações séricas aumentam ao longo da gestação em cerca de 10 vezes até o final do terceiro trimestre $^{56,57}$. Em relação ao hCG, sua proporção, menor que $10 \%$ no primeiro trimestre, alcança $30-$ $60 \%$ no termo. Nas mulheres não grávidas, e homens, a produção da subunidade alfa livre é hipofisária e não reflete apenas a produção de hCG, aumentando em 5 vezes da pré para a pós-menopausa $^{42,53}$. As concentrações urinárias são de 5 a 7 vezes maiores que no soro. Vários laboratórios desenvolveram ensaios, não comercializados, para detectar $\alpha$ hCG, mostrando reação cruzada menor que $5 \%$ com as moléculas variantes de hCG intacta e $\beta \mathrm{hCG}^{1,19,52}$. Ainda que dois ensaios para quantificar apenas a F- $\alpha$ hCG estejam disponiveis, o uso clínico desta subunidade como marcador tumoral tem despertado menor interesse, mas pode ser útil na detecção precoce de tumores, principalmente dos hipofisários não secretores, das neoplasias pulmonares, insulinomas e carcinóides gástricos ${ }^{58}$.

\section{Fragmento-Núcleo da Subunidade Beta da Gonadotrofina Coriônica Humana}

O fragmento-núcleo da $\beta$ hCG (CF- $\beta$ hCG, C do inglês core) tem peso molecular de aproximadamente 14.000 daltons. Seu núcleo protéico contém 73 aminoácidos estruturados em duas pequenas cadeias polipeptídicas, resíduos 6 a 40 e 55 a 92 da $\beta$ hCG, ligadas por cinco pontes dissulfídicas não covalentes. Sua estrutura glicídica contém duas ramificações de oligossacarídeos complexos N-ligados fixos aos peptídeos Asn-13 e Asn-30 ${ }^{59,60}$. Estas ramificações de carboidratos são também degradadas, contendo cada uma apenas 5 a 11 resíduos de açúcar ${ }^{60}$. Além disso, $30 \%$ das moléculas de CF-ßhCG são completamente deglicosiladas $^{61}$. A disponibilidade atual de preparações altamente purificadas deste fragmento permitiram o desenvolvimento de ensaios específicos destituídos de reação cruzada com as outras moléculas relacionadas ao hCG para sua quantificação ${ }^{62,63}$. Ensaios específicos imunoenzimáticos e radiométricos com reação cruzada negligenciável com as outras formas variantes de hCG podem ser obtidos comercialmente para uso clínico ${ }^{8,61}$.

$\mathrm{O} \mathrm{CF}-\mathrm{hCG}$ pode ser detectado em grandes quantidades na urina de gestantes normais, urina de mulheres não grávidas, neoplasia trofoblástica gestacional, líquido amniótico, líquido das vesículas na mola hidatiforme, líquido folicular ovariano após uso de hCG para indução da ovulação, urina de recém-nascidos, sêmen, placenta e extratos de vários tecidos ${ }^{10,64}$. Quantidades muito pequenas podem ser detectadas no soro de gestantes ou mesmo indivíduos não gestantes ${ }^{65}$. Quantitativamente a urina é a fonte mais importante de CF- $\beta$ hCG, refletindo papel ativo do rim no catabolismo de $\mathrm{hCG}^{7}$. É produto estável da degradação renal de hCG na seqüência hCG $\rightarrow$ hCG clivada $\rightarrow \beta$ hCG clivada $\rightarrow \beta$ hCG livre $\rightarrow$ CF- $\beta h_{C G}{ }^{66,67}$. Tem concentrações de 2 a 10 vezes maior que a molécula de hCG intacta na urina, em termos de molaridade ${ }^{68}$. Do mesmo modo que ocorre com a molécula de hCG, os níveis de CF- $\beta$ hCG sofrem modificações diurnas, com maiores concentrações pela manhã e menores no final da tarde ${ }^{69}$.

Na segunda metade da gravidez sua concentração na urina varia entre 5,6 e $372,5 \mathrm{nmol} / \mathrm{L}$ e representa entre $15-750 \%$ da imunorreatividade da hCG total, ou seja, forma intacta mais o CF$\beta \mathrm{hCG}^{68}$. Amostras de urina obtidas entre a $6^{\mathrm{a}}$ e a $41^{\text {a }}$ semana de gravidez mostram concentrações máximas de CF- $\beta$ hCG entre a $8^{\mathrm{a}}$ e a $15^{\mathrm{a}}$ semana, diminuindo entre a $20^{\mathrm{a}}$ e a $29^{\mathrm{a}} 68$. A produção em moles de $\mathrm{CF}-\beta$ hCG é sempre maior do que a uni- 
dade (excesso entre 160-957\%), principalmente entre a $9^{a}$ e a $19^{a}$ semana de gravide $z^{68}$.

Estudo longitudinal comparando as diferentes formas moleculares da hCG nas primeiras seis semanas de gravidez mostrou maior secreção inicial das moléculas de hCG intacta e F- $\beta$ hCG. O CF- $\beta$ hCG emergiu como a forma predominante na $5^{\mathrm{a}}$ semana pós-concepção. No entanto, ainda que seu aumento ocorra depois do aumento das moléculas de hCG e $\beta$ hCG no início da gravidez, os níveis de CF- $\beta$ hCG não sofrem variação na sua concentração na mesma dimensão que as outras moléculas, tornando os resultados mais consistentes com a sua dosagem ${ }^{43}$.

O CF- $\beta$ hCG tem sido utilizado para discriminação entre gestações normais intra-uterinas e prenhezes ectópicas, mostrando maior poder discriminativo entre as duas condições que as moléculas de hCG intacta e F- $\beta$ hCG ${ }^{69}$. Em múltiplos da mediana, normalizada para creatinina, entre a $2^{\text {a }}$ e a $5^{\mathrm{a}}$ semana, os valores variam entre 0,15 e 0,008. Quando o CF-hCG foi empregado para prever abortamentos espontâneos, os resultados, em MoM, variaram entre 0,11 e 0,016, mostrando valor preditivo positivo de $76 \%$ nas duas condições clínicas ${ }^{70}$. No segundo trimestre, o fragmento foi testado também para prever o crescimento fetal, e os niveis mostraram ser maiores nas gestações que evoluem para fetos pequenos em relação à idade gestacional com sensibilidade de $78 \%$ e especificidade de $70 \%{ }^{71}$.

Uma vez que outros marcadores séricos utilizados para prever a evolução da gravidez antes da $6^{\text {a }}$ semana têm se mostrado ineficazes, enquanto o CF- $\beta$ hCG mostra correlação positiva com a idade gestacional entre a $4^{\mathrm{a}}$ e a $6^{\mathrm{a}}$ semana apenas em gestações com boa evolução, tem se proposto sua utilização como método de escolha nesta fase da gravide $z^{72}$. Gestações com pré-eclâmpsia também cursam com níveis de CF- $\beta$ hCG elevados, provavelmente como resposta secundária da função secretora anormal do trofoblasto ${ }^{39}$. Estabeleceu-se também correlação entre os níveis de CF- $\beta$ hCG no segundo trimestre e desenvolvimento posterior de pré-eclâmpsia, sendo que o risco aumenta com o aumento das concentrações do fragmento ${ }^{35}$. Nesta condição, o risco relativo eleva-se de $2,1 \mathrm{em}$ gestações com níveis de $\mathrm{CF}-\beta \mathrm{hCG} \geq 2,0 \leq 4,0 \mathrm{MoM}$ para 5,2 em casos de CF- $\beta$ hCG com níveis $>4,0$ MoM da mediana encontrada em gestação normal.

Existem fortes evidências da importância do CF- $\beta$ hCG para a detecção de anormalidades cromossômicas no segundo trimestre, parecendo destituída de valor sua dosagem no primeiro. Taxas de detecção da síndrome de Down entre 60 e 80\% têm sido relatadas no segundo trimestre ${ }^{73}$. Estudo prospectivo recente efetuado entre a $15^{\mathrm{a}}$ e a $24^{\mathrm{a}}$ sema- na de gestação mostrou que niveis de $\mathrm{CF}-\beta \mathrm{hCG}$ iguais ou superiores ao $97^{\circ}$ percentil têm sensibilidade de $61 \%$ e taxa de falso-positivo de $3,2 \%{ }^{74}$. A maioria dos estudos nos quais se examina a eficácia da dosagem de CF- $\beta$ hCG para a detecção da síndrome de Down relata sensibilidade entre 41 e 93\% e especificidade entre 90 e 95\%. Em MoM, os valores de CF- $\beta$ hCG têm estado entre 1,06-2,91 no primeiro trimestre e 1,06-12,89 no segundo ${ }^{75}$. Equivalência ou superioridade deste marcador, em relação ao teste triplo, na detecção de fetos com síndrome de Down tem sido encontrada ${ }^{74}$.

Além da produção renal, tecido placentário, vesículas molares ou coriocarcinoma também secretam $\mathrm{CF}-\beta \mathrm{hCG}^{11,64,76}$. Este fragmento-núcleo da $\beta$ hCG é de relevância clínica também no acompanhamento de gestantes com neoplasia trofoblástica ou indivíduos com câncer, seja este ginecológico ou não ${ }^{77}$. Estima-se ser possível detectar $\mathrm{CF}$ 3 hCG em $48 \%$ dos pacientes com câncer cervical, $38 \%$ no carcinoma endometrial e $84 \%$ dos carcinomas ovarianos ${ }^{78}$. CF- $\beta$ hCG identifica cerca de 11-18\% dos indivíduos com neoplasia cervical intraepitelial $^{79}$. De um modo geral, no câncer cervical a dosagem do CF- $\beta$ hCG tem sensibilidade entre 51 e $84 \%{ }^{80}$ e, quando presente, indica pior prognóstico ${ }^{81}$. Na identificação do câncer pulmonar, o CF-ßhCG mostra sensibilidade de $48 \%$ nos estágios inicias e de $72 \%$ nos estágios mais avançados da doença ${ }^{82}$.

\section{Conclusão}

É comum a ocorrência de modificações na estrutura e composição dos carboidratos e cadeia peptídica da gonadotrofina coriônica humana nos líquidos biológicos. Esta complexidade estrutural, resultando na formação de múltiplas formas moleculares de hCG, responde pelos resultados inconsistentes freqüentemente observados entre os ensaios disponíveis. A identificação individual do dímero alfa-beta e formas variantes de hCG, subunidades alfa e beta livres e fragmentos da subunidade beta com ensaios específicos tem relevante aplicação clínica no prognóstico da gravidez, rastreamento de intercorrências como prenhez ectópica, pré-eclâmpsia e crescimento intrauterino restrito, detecção de anomalias cromossômicas êmbrio-fetais e identificação ou seguimento de neoplasia trofoblástica gestacional. Além disso, a dosagem destas moléculas como marcadores bioquímicos de tumores de diferentes origens histológicas é útil. Há, no entanto, necessidade de divulgação mais ampla e uso dos novos imunoensaios, mais específicos e sensíveis. 


\section{Referências}

1. Norman RJ, Buck RH, Medeiros SF. Measurement of human chorionic gonadotrophin (hCG): indications and techniques for the clinical laboratory. Ann Clin Biochem. 1990;27(Pt 3):183-94.

2. Medeiros SF. Heterogeneidade do hormônio coriogonadotrófico. Aspectos básicos e importância clínica. GO Atual. 1997;6(3):8-15.

3. Gray CJ. Glycoprotein gonadotropins. Structure and synthesis. Acta Endocrinol Suppl (Copenh). 1998;228:20-7.

4. Hussa RO. Human chorionic gonadotropin, a clinical marker: review of its biosynthesis. Ligand Rev. 1981;3 Suppl 2:1-44.

5. Jameson JL, Hollenberg AN. Regulation of chorionic gonadotropin gene expression. Endocr Rev. 1993;14(2):203-21.

6. O’Connor JF, Birken S, Lustbader JW, Krichevsky A, Chen Y, Canfield RE. Recent advances in the chemistry and immunochemistry of human chorionic gonadotropin: impact on clinical measurements. Endocr Rev. 1994;15(5):650-83.

7. Norman RJ, Buchholz MM, Somogyi AA, Amato F. hCG $\beta$-core fragment is a metabolite of hCG: evidence from infusion of recombinant hCG. J Endocrinol. 2000;164(3):299-305.

8. Cole LA. hCG, its free subunits and its metabolites. Roles in pregnancy and trophoblastic disease. J Reprod Med 1998;43(1):3-10.

9. Birken S, Kovalevskaya G, O’Connor J. Metabolism of hCG and hLH to multiple urinary forms. Mol Cell Endocrinol. 1996;125(1-2):121-31.

10.Conn PM, Conti M, Harwood JP, Dufau ML, Catt KJ. Internalisation of gonadotrophin-receptor complex in ovarian luteal cells. Nature. 1978;274(5671):598-600.

11.de Medeiros SF, Amato F, Bacich D, Wang L, Matthews CD, Norman RJ. Distribution of the bcore human chorionic gonadotrophin fragment in human body fluids. J Endocrinol. 1992;135(1):17588.

12. Muller F, Savey L, Le Fiblec B, Bussieres L, Ndayizamba G, Colau JC, et al. Maternal serum human chorionic gonadotropin level at fifteen weeks is a predictor for preeclampsia. Am J Obstet Gynecol. 1996;175(1):37-40.

13.Banerjee S, Smallwood A, Chambers AE, Papageorghiou A, Loosfelt H, Spencer K, et al. A link between high serum levels of human chorionic gonadotropin and chorionic expression of its mature functional receptor (LHCGR) in Down's syndrome pregnancies. Reprod Biol Endocrinol. 2005;3(1):2538.
14. Cole LA, Sutton JM, Higgins TN, Cembrowski GS. Between method variation in human chorionic gonadotropin test results. Clin Chem. 2004;50(5):874-82.

15. Birken S, Berger P, Bidart JM, Weber M, Bristow A, Norman R, et al. Preparation and characterization of new WHO reference reagents for human chorionic gonadotropin and metabolites. Clin Chem. 2003;49(1):144-54.

16. Kharfi A, Giguere C, De Grandpre P, Moutquin JM, Forest JC. Human chorionic gonadotropin (hCG) may be a marker of systemic oxidative stress in normotensive and preeclamptic term pregnancies. Clin Biochem. 2005;38(8):717-21.

17. Gurbuz Z, Karateke A, Mengulluoglu M, Gedikbasi A, Ozturkmen M, Kabaca C, et al. Can serum hCG values be used in the differential diagnosis of pregnancy complicated by hypertension ? Hypertens Pregnancy. 2004;23(1):1-12.

18.Roiz-Hernandez J, de J Cabello-Martinez J, Fernandez-Mejia M. Human chorionic gonadotropin levels between 16 and 21 weeks of pregnancy and prediction of pre-eclampsia. Int $\mathrm{J}$ Gynaecol Obstet. 2006;92(2):101-5.

19. Crocker IP, Tansinda DM, Baker PN. Altered cell kinetics in cultured placental villous explants in pregnancies complicated by pre-eclampsia and intrauterine growth restriction. J Pathol. 2004;204(1):11-8.

20.Lottersberger C, Hoermann R, Mann K, Schwarz S, Berger P. Tumor- and pregnancy- derived isoforms of humam chorionic gonadotropin: biological and diagnostic relevance. Horm Res. 2003;59(3):125-34.

21.Hoshi S, Suzuki K, Ishidoya S, Ohyama C, Sato M, Namima T, et al. Significance of simultaneous determination of serum human chorionic gonadotropin (hCG) and $\mathrm{hCG}$ - beta in testicular tumor patients. Int J Urol. 2000;7(6):218-23.

22.Stenman UH, Alfthan H, Hotakainem K. Human chorionic gonadotropin in cancer. Clin Biochem. 2004;37(7):549-61.

23. Spencer C, Crossley JA, Aitken DA, Nix AB, Dunstan FD, Williams K. Temporal changes in maternal serum biochemical markers of trisomy 21 across the first and second trimester of pregnancy. Ann Clin Biochem. 2002;39(Pt 6):567-76.

24. Nicolaides KH. First-trimester screening for chromosomal abnormalities. Semin Perinatol. 2005;29(4):190-4.

25. Canick JA, MacRae AR. Second trimester serum markers. Semin Perinatol. 2005;29(4):203-8.

26. Hershkovitz R, Erez O, Sheiner E, Landau D, Mankuta D, Mazor M. Elevated maternal midtrimester chorionic gonadotropin $>$ or $=4 \mathrm{MoM}$ is associated with fetal cerebral blood flow 
redistribution. Acta Obstet Gynecol Scand. 2003;82(1):22-7 .

27.Huang T, Alberman E, Wald N, Summers AM. Triploidy identified through second-trimester serum screening. Prenat Diagn. 2005;25(3):229-33.

28. Elliott MM, Kardana A, Lustbader JW, Cole LA. Carbohydrate and peptide structure of the alphaand beta- subunits of human chorionic gonadotropin from normal and aberrant pregnancy and choriocarcinoma. Endocrine. 1997;7(1):15-32.

29. Cole LA, Khanlian SA, Sutton JM, Davies S, Stephens ND. Hyperglycosylated hCG (invasive trophoblast antigen, ITA) a key antigen for early pregnancy detection. Clin Biochem. 2003;36(8):64755 .

30. Birken S, Krichevsky A, O’Connor J, Schalatterer J, Cole L, Kardana A, et al. Development and characterization of antibodies to a nicked and hyperglycosylated form of hCG from a choriocarcinoma patient: generation of antibodies that differentiate between pregnancy hCG and choriocarcinoma hCG. Endocrine. 1999;10(2):137-44.

31.Pandian R, Lu J, Ossolinska-Plewnia J. Fully automated chemiluminometric assay for hyperglycosylated human chorionic gonadotropin (invasive trophoblast antigen). Clin Chem. 2003;49(5):808-10.

32. Spencer K, Talbot JA, Abushoufa RA. Maternal serum hyperglycosylated human chorionic gonadotrophin (HhCG) in the first trimester of pregnancies affected by Down syndrome, using a sialic acid-specific lectin immunoassay. Prenat Diagn. 2002;22(8):656-62.

33. Wald NJ, Rodeck C, Hackshaw AK, Walters J, Chitty L, Mackinson AM. First and second trimester antenatal screening for Down's syndrome the result of the serum, urine and ultrasound screening study (SURUSS). J Med Screen. 2003;10(2):56-104.

34. Cole LA, Shahabi S, Oz UA, Bahado-Singh RO, Mahoney MJ. Hyperglycosylated human chorionic gonadotropin (invasive trophoblast antigen) immunoassay: a new basis for gestational Down syndrome screening. Clin Chem. 1999;45(12):210919.

35. Bahado-Singh RO, Oz AU, Kingston JM, Shahabi S, Hsu CD, Cole LA.The role of hyperglycosylated hCG in trophoblast invasion and the prediction of subsequent pre-eclampsia. Prenat Diagn. 2002;22(6):478-81.

36. Cole LA, Kardana A, Park SY, Braunstein GD. The deactivation of hCG by nicking and dissociation. J Clin Endocrinol Metab. 1993;76 (3):704-10.

37. Cole LA, Kardana A. Discordant results in human chorionic gonadotropin assays. Clin Chem. 1992;38(2):263-70.
38. Kovalevskaya G, Birken S, Kakuma T, Schlatterer $\mathrm{J}$, O'Connor JF. Evaluation of nicked human chorionic gonadotropin content in clinical specimens by a specific immunometric assay. Clin Chem. 1999;45(1):68-77.

39.Lee IS, Chung DY, Cole LA, Copel JA, Isozaki T, Hsu CD. Elevated serum nicked and urinary betacore fragment hCG in preeclamptic pregnancies. Obstet Gynecol. 1997;90(6):889-92.

40.Prieto JA, Panyutich AV, Heine RP. Neutrophil activation in pre-eclampsia: are defensins and lactoferrin elevated in preeclamptic patients ? J Reprod Med. 1997;42(1):29-32.

41.Hoermann R, Berger P, Spoettl G, Gillesberger F, Kardana A, Cole LA, et al. Immunological recognition and clinical significance of nicked human chorionic gonadotropin in testicular cancer. Clin Chem. 1994;40(12):2306-12.

42. Norman RJ, Menabawey M, Lowings C, Buck RH, Chard T. Relationship between blood and urine concentrations of intact human chorionic gonadotropin and its free subunits in early pregnancy. Obstet Gynecol. 1987;69(4):590-3.

43. McChesney R, Wilcox AJ, O’Connor JF, Weinberg $\mathrm{CR}$, Baird DD, Schlatterer JP, et al. Intact hCG, free $\mathrm{hCG}$ b subunit and $\mathrm{hCG}$ b core fragment: longitudinal patterns in urine during early pregnancy. Hum Reprod. 2005;20(4):928-35.

44.Spencer K. First trimester maternal serum screening for Down's syndrome: an evaluation of the DPC Immulite 2000 free beta-hCG and pregnancy-associated plasma protein-A assays. Ann Clin Biochem. 2005;42(Pt 1):30-40.

45. Ong CY, Liao AW, Spencer K, Munim S, Nicolaides KH. First trimester maternal serum free beta human chorionic gonadotropin and pregnancy associated plasma protein A as predictors of pregnancy complications. BJOG. 2000;107(10):1265-70.

46. Vaillant P, David E, Constant I, Athmani B, Devulder G, Fievet P, et al. Validity in nulliparas of increased b-human chorionic gonadotropin at mid-term for predicting pregnancy-induced hypertension complicated with proteinuria and intrauterine growth retardation. Nephron. 1996;72(4):577-63.

47. Gillot DJ, Iles RK, Chard T. The effects of â- human chorionic gonadotrophin on the in vitro growth of bladder cancer cells. Br J Cancer. 1996;73(3):323-6.

48.Spencer K, Liao AW, Skentou H, Cicero S, Nicolaides KH. Screening for triploidy by fetal nuchal translucency and maternal serum free b-hCG and PAPP-A at 10-14 weeks of gestation. Prenat Diagn. 2000;20(6):495-9.

49. Falcon O, Auer M, Gerovassili A, Spencer K, Nicolaides KH. Screening for trisomy 21 by fetal tricuspid regurgitation, nuchal translucency and maternal serum free beta-hCG and PAPP-A at $11+0$ 
to $13+6$ weeks. Ultrasound Obstet Gynaecol. 2006;27(2):151-5.

50. Hallahan T, Krantz D, Orlandi F, Rossi C, Curcio P, Macri S, et al. First trimester biochemical screening for Down syndrome: free beta hCG versus intact hCG. Prenat Diagn. 2000;20(10):785-9.

51.Spencer K, Aitken DA, Macri JN, Buchanan PD. Urine free beta hCG and beta core in pregnancies affected by Down's syndrome. Prenat Diagn. 1996;16(7):605-13.

52.Spencer K, Crossley JA, Aitken DA, Nicolaides KH. Second-trimester levels of pregnancy-associated plasma protein-A and free b-hCG in pregnancies with trisomy 13. Prenat Diagn. 2005;25(5):358-61.

53. Norman RJ, Haneef R, Buck RH, Joubert SM. Measurement of free alpha subunit of human glycoprotein hormones by a monoclonal antibodybased immunoradiometric assay, and further exploration of antigenic sites on the choriogonadotropin molecule. Chin Chem. 1987;33(7):1147-51.

54. Norman RJ, Lowings C, Oliver T, Chard T. Human chorionic gonadotrophin and subunits heterogeneity in serum of male patients with tumours of the genital tract. Clin Endocrinol (Oxf). 1985;23(1):2534 .

55. Blithe DL, Nisula BC.Variations in the oligosaccharides on free and combined á - subunits of human choriogonadotropin in pregnancy. Endocrinology. 1985;117(5):2218-28.

56. Blithe DL, Richards RG, Skarulis MC. Free alpha molecules from pregnancy stimulate secretion of prolactin from human decidual cells: a novel function for free alpha in pregnancy. Endocrinology. $1991 ; 129(4): 2257-9$.

57. Skarulis MC, Wehmann RE, Nisula BC, Blithe DL. Glycosylation changes in human chorionic gonadotropin and free alpha subunit as gestation progresses. J Clin Endocrinol Metab. 1992;75(1):916.

58. Ridgway EC, Klibanski A, Ladenson PW, Clemmons D, Beitins IZ, McArthurr JW, et al. Pure alphasecreting pituitary adenomas. N Engl J Med. 1981;304(21):1254-9.

59. Birken S, Armstrong EG, Kolks MA, Cole LA, Agosto GM, Krichevsky A, et al. Structure of human chorionic gonadotropin beta-subunit fragment from pregnancy urine. Endocrinology. 1988;123(1):572-83.

60.de Medeiros SF, Amato F, Matthews CD, Norman RJ. Molecular heterogeneity of the $\beta$-core fragment of human chorionic gonadotrophin. J Endocrinol. 1993;139(3):519-32.

61. Blithe DL, Wehman RE, Nisula BC. Beta-core chemical and clinical properties. Trends Endocrinol Metab. 1990; 1(8):394-8.
62.Krichevsky A, Birken S, O' Connor J, Bikel K, Schlatterer J, Yi C, et al. Development and characterization of a new, highly specific antibody to the human chorionic gonadotropin-b fragment. Endocrinology. 1991;128(3):1255-64.

63.de Medeiros SF, Amato F, Mattheus CD, Norman RJ. Comparison of specific immunoassays for detection of the â-core human chorionic gonadotropin fragment in body fluids. J Endocrinol. 1992;135(1):161-74.

64. Khan S, Katabuchi H, Araki M, Ohba T, Koizumi T, Okamura $\mathrm{H}$, et al. The molar vesicle fluid contains the $\beta$-core fragment of human chorionic gonadotropin. Placenta. 2000;21(1):79-87.

65. Alfthan H, Stenman UH. Pregnancy serum contains the beta core fragment of human choriogonadotropin. J Clin Endocrinol Metab. 1990;70(3):783-7.

66. de Medeiros SF, Amato F, Norman RJ. Stability of immunoreactive beta-core fragment of hCG. Obstet Gynecol. 1991;77(1):53-9.

67. Cole LA. b-core fragment (b-core, UGP or UGF). Tumour Marker Update. 1994;6(1):69-75.

68.de Medeiros SF, Amato F, Matthews CD, Norman RJ. Urinary concentrations of beta core fragment of hCG throughout pregnancy. Obstet Gynecol. 1992;80(2):223-8.

69. Rotmensch S, Celentano C, Elliger N, Sadan O, Lehman D, Golan A, et al. Diurnal variation of human chorionic gonadotropin b-core fragment concentrations in urine during second trimester of pregnancy. Clin Chem. 2001;47(9):1715-7.

70. Cole LA, Isozaki T, Jones EE. Urine beta-core fragment, a potential screening test for ectopic pregnancy and spontaneous abortion. Fetal Diagn Ther. 1997;12(6):336-9.

71.Bahado-Singh R, Oz AU, Flores D, Hsu C, Mari G, Cole LA. Maternal urine beta-core hCG fragment level and small for gestational age neonates. Obstet Gynecol. 2000;95(5):662-6.

72. Cardwell L, Kowalczyk CL, Krivchenia EL, Leon J, Evans MI. Urinary beta-core fragment as a predictor of abnormal pregnancy at 4-6 weeks' gestation. Fetal Diagn Ther. 1997;12(6):340-2.

73. Isozaki T, Palomaki GE, Bahado-Singh RO, Cole LA. Screening for Down syndrome pregnancy using betacore fragment: prospective study. Prenat Diagn. 1997;17(5):407-13.

74. Bahado-Singh R, Oz AU, Rinne K, Hunter D, Cole LA, Mahoney MJ, et al. Elevated maternal urine level of $\beta$-core fragment of human chorionic gonadotropin versus serum triple test in the second-trimester detection of Down syndrome. Am J Obstet Gynecol. 1999;181(4):929-33.

75.Hsu JJ, Spencer K, Hung TH, Hsieh TT, Soong YK. Second-trimester maternal urine human chorionic 
gonadotropin $\beta$-core fragment concentrations in Asian pregnancies with fetal chromosomal abnormalities. Hum Reprod. 1999;14(9):2381-5.

76. Okamato T, Matsuo K, Niu R, Osawa M, Suzuki H. Human chorionic gonadotropin (hCG) $\beta$-core fragment is produced by degradation of hCG or free hCG in gestational trophoblastic tumors: a possible marker for early detection of persistent postmolar gestational trophoblastic disease. J Endocrinol. 2001;171(3):435-43.

77. Norman RJ, Buck RH, Aktar B, Mayet N, Moodley J. Detection of a small molecular species of human chorionic gonadotropin in the urine of patients with carcinoma of the cervix and cervical intraepithelial neoplasia: comparison with other assays for human chorionic gonadotropin and its fragments. Gynecol Oncol. 1990;37(2):254-9.

78. Nishimura R, Koizumi T, Yokotani T, Tamiguchi R, Morisue K, Yoshimura M, et al. Molecular heterogeneity of hCG b-related glycoproteins and the clinical relevance in trophoblastic and non- trophoblastic tumors. Int $\mathrm{J}$ Gynaecol Obstet. 1998;60 Suppl 1:S29-32.

79. Norman RJ, de Medeiros SF, Amato F, Davis G, Davy M. â-core fragment of human chorionic gonadotropin in cervical intraepithelial neoplasia (CIN). Gynecol Oncol. 1993;49(1):16-8.

80. Ngan HY, Yeung WS, Cheng GT, Wong LC, Medeiros $\mathrm{SF}$, Norman RJ, et al. Problems in the use of urinary hCG beta-core as a tumor marker in gynecologic cancer. Int J Gynecol Cancer. 1995;5(1):15-9.

81. Carter PG, Iles RK, Neven P, Ind TE, Shepherd JH, Chard T. The prognostic significance of urinary beta core fragment in premenopausal women with carcinoma of the cervix. Gynecol Oncol. 1994;55(2):271-6.

82. Yoshimura M, Nishimura R, Murotani A, Miyamoto Y, Nakagawa T, Hasegawa K, et al. Assessment of urinary beta-core fragment of human chorionic gonadotropin as a new marker of lung cancer. Cancer. 1994;73(11):2745-52. 